\title{
A bZIP protein, Sisterless-a, collaborates with bHLH transcription factors early in Drosophila development to determine sex
}

\author{
James W. Erickson and Thomas W. Cline \\ Division of Genetics, Department of Molecular and Cell Biology, University of California, Berkeley, California 94720 USA
}

Sexual identity in Drosophila is determined by zygotic X-chromosome dose. Two potent indicators of $\mathrm{X}$-chromosome dose are sisterless-a $($ sis-a) and sisterless- $\boldsymbol{b}(\mathbf{s i s}-\mathrm{b})$. Genetic analysis has shown that a diplo-X dose of these genes activates their regulatory target, the feminizing switch gene Sex-lethal (Sxl), whereas a haplo-X dose leaves $S x l$ inactive. sis-b encodes a transcriptional activator of the bHLH family that dimerizes with several other HLH proteins required for the proper assessment of $X$ dose. Here, we report that sis-a encodes a bZIP protein homolog that functions in all somatic nuclei to activate $S x I$ transcription. In contrast with other elements of the sex-determination signal, the functioning of this transcription factor in somatic cells may be specific to $X$-chromosome counting. Using in situ hybridization, we determined the time course of sis-a, sis-b, and Sxl transcription during the first few hours after fertilization. The pattern of sis-a RNA accumulation is very similar to that for sis-b, with a peak in nuclear cycle 12 at about the time of onset of $S x l$ transcription. Considered in the context of other studies, these results suggest that the ability to distinguish one $\mathrm{X}$ from two is attributable to combinatorial interactions between bZIP and bHLH proteins and their target, $S \mathbf{x l}$, as well as to positive and negative interactions with maternally supplied and zygotically produced proteins.

[Key Words: Sex determination; X/A ratio; sisterless genes; Sex-lethal; bZIP proteins; bHLH proteins]

Received May 14, 1993; revised version accepted July 7, 1993.

In 1916 it was reported that genes are on chromosomes and that sex in Drosophila melanogaster is determined by the number of X chromosomes, with two X's signaling female development and one $X$ signaling the male alternative (Bridges 1916). More than half a century later, the specific genetic elements of this quantitative developmental signal began to be identified /Cline 1988; Torres and Sanchez 1989). Identification of these sexdetermination signal elements awaited the discovery of their regulatory target, the X-linked gene Sex-lethal (Sxl) and the understanding that $S x l$ coordinately controls both sex determination and the vital process of X-chromosome dosage compensation (Cline 1979, 1983, 1984; Lucchesi and Skripsky 1981; Gergen 1987). Sxl controls all aspects of somatic sexual dimorphism through its effects on subordinate regulatory genes with more specialized functions (see McKeown et al. 1988; Gorman et al. 1993). Female differentiation is a consequence of $S x l$ being turned on in diplo- $\mathrm{X}$ individuals, whereas male differentiation takes place in haplo- $X$ individuals because $S x l$ remains off. Genetic analysis showed that the sexspecific regulation of $S_{x} l$ is already established by the blastoderm stage (Sanchez and Nöthiger 1983; Cline 1984; Gergen 1987), the point in Drosophila develop- ment when cells are first formed. Thereafter, $S x l$ activity is required continuously to maintain this early sexual pathway choice (Sanchez and Nöhiger 1982; Cline 1984; Maine et al. 1985). From the blastoderm stage through the rest of development, the on/off regulation of $S \times 1$ is at the level of RNA processing through the operation of a direct positive feedback loop involving the $\mathrm{Sxl}$ protein (Bell et al. 1988, 1991; Samuels et al. 1991). Sxl is transcribed in both sexes from a "maintenance" promoter, Pm (also called the late promoter), but only females splice the resulting transcripts into functional mRNAs, as only females have the $\mathrm{Sxl}$ protein that is required to remove a male-specific exon that would otherwise abort translation.

Although this RNA splicing control is an essential aspect of Sxl regulation throughout nearly all of development, the primary sex-determination signal itself does not act on $S x l$ RNA splicing but, rather, on $S x l$ transcription and does so before the cellular blastoderm stage (Keyes et al. 1992). This transcriptional effect involves a different $S x l$ promoter, $P e$ (for establishment or early), that is active only before cellularization, before the activation of $S x l_{P m}$ in both sexes. In contrast to transcripts derived from $S x l_{P m}$, transcripts derived from $S x l_{P e}$ are 
spliced into functional mRNAs even in the absence of Sxl protein (Keyes et al. 1992). The two X chromosomes in females activate $S x l_{P e}$, thereby generating a pulse of Sxl protein that will establish the productive Sxl RNA splicing mode once $S \times l_{P e}$ shuts down and $S x l_{P m}$ becomes active. In contrast, males with their single $\mathrm{X}$ chromosome are unable to activate $S x l_{P e}$. As a consequence, when $S x l_{P m}$ becomes active, no Sxl protein is present and transcripts are spliced nonproductively from that point on. The regulation of $S x l$ is summarized in Figure 1.

The fruit fly sex-determination signal has been viewed traditionally as an X/A ratio, since the dose of $\mathrm{X}$ chromosomes was shown to be counted with reference to the number of sets of autosomes (Bridges 1921, 1925). With this model there would be female-determining "numerator" genes on the $\mathrm{X}$ chromosome acting as positive regulators of $S x l$ and corresponding male-determining "denominator" genes on the autosomes acting as negative regulators. It is now clear that the zygotic X chromosome dose is also measured with reference to a background of positive regulators of $S x l$ such as daughterless (da), and negative regulators of $S x l$ such as extramacrochaetae (emc), that are produced by the mother and supplied to the egg during oogenesis (Cline 1978, 1980; Younger-Shepherd et al. 1992).

Two strong numerator elements have been identified, sisterless- $a$ and sisterless- $b$ (sis- $a$ and sis- $b$ ), whose genetic manipulation generates sex-specific lethal phenotypes attributable to misregulation of $\mathrm{Sxl}$ (Cline 1988; Torres and Sanchez 1989). More recently, two weaker numerator elements have been discovered: runt (Duffy and Gergen 1991; Torres and Sanchez 1992) and sis-c (Cline 1993). A gene called deadpan (dpn) acts as a neg- ative regulator of $S x l$ and fits the criteria for a denominator element (Younger-Shepherd et al. 1992).

The first X/A element to be characterized at the molecular level was $s i s-b$. sis-b function is provided by the protein product of the T4(scute) transcription unit of the Achaete-Scute Complex (Torres and Sanchez 1989, 1991; Parkhurst et al. 1990; Erickson and Cline 1991). T4 encodes a member of the basic helix-loop-helix (bHLH) family (Villares and Cabrera 1987; Murre et al. 1989a). bHLH proteins are transcriptional activators characterized by a HLH dimerization motif, a basic domain involved in DNA binding, and a promiscuous ability to form heterodimers (Murre et al. 1989a,b). Remarkably, the two known maternal regulatory factors, $d a$ and emc, and the one autosomal zygotic factor, $d p n$, also encode HLH proteins (Murre et al. 1989a; Younger-Shepherd et al. 1992).

These discoveries led to the proposal that the X-chromosome counting process in Drosophila might involve subunit interactions between only positive and negative HLH proteins (Parkhurst et al. 1990). The numerator element runt was an exception to this rule, as it encodes a transcriptional regulator of unknown biochemical function that is homologous to a proto-oncogene responsible for a subtype of acute myeloid leukemia (Kania et al. 1990; Daga et al. 1992). However, runt is also different from sis-b in other ways: Its participation in the counting process is far weaker, and it only appears to participate in the sex signal over a spatially restricted domain of the young embryo (Duffy and Gergen 1991).

It is notable that none of these five genes is specific to sex determination and that all five are intimately involved in neuronal development or function. Because of this, it has been suggested that an entire neural regula-

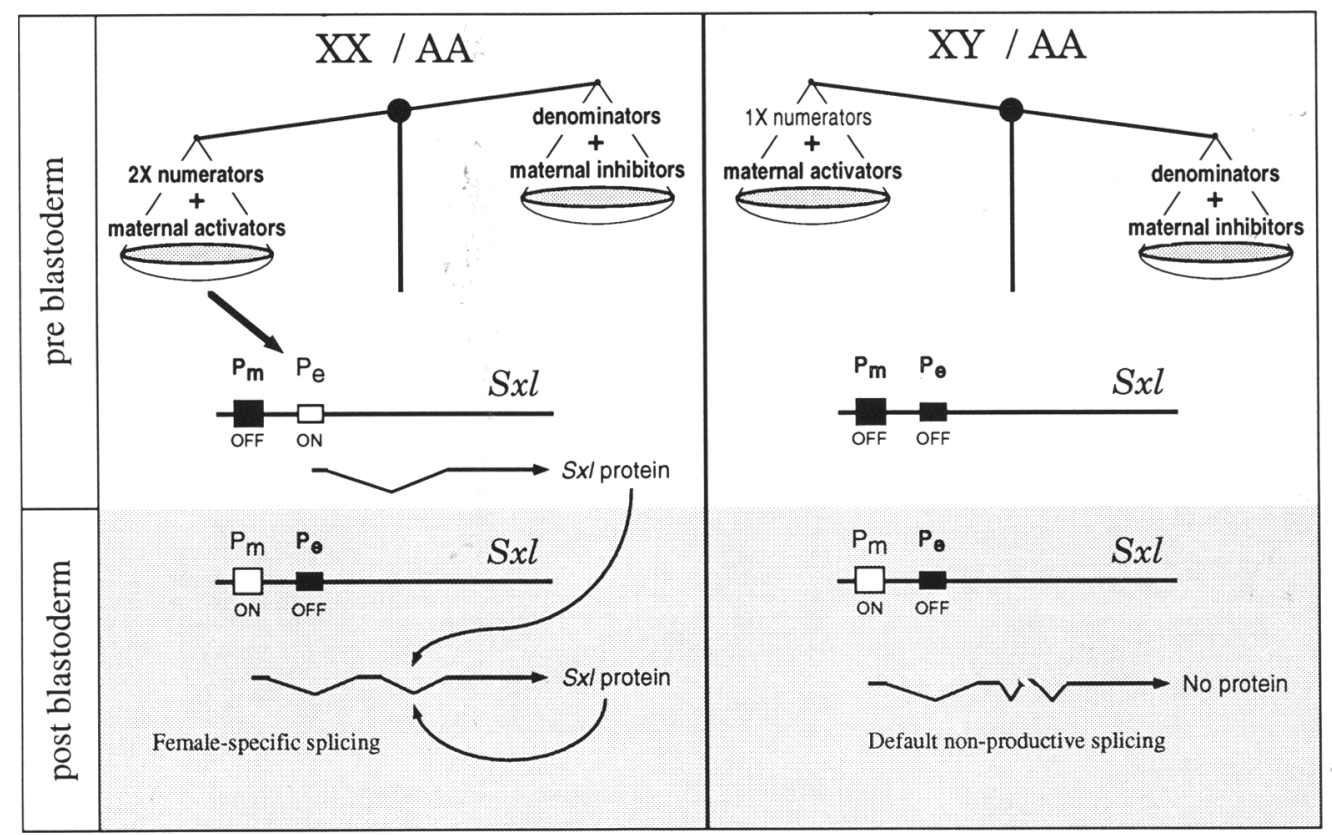

Figure 1. Model for the initiating events in sex determination. 
tory network might have been co-opted during evolution for use as a primary sex-determination signal (YoungerShepherd et al. 1992). Curiously, even the closest homolog of Sxl in the fly, elav is involved in neural development (Robinow et al. 1988).

Is the other major numerator element of the sex-determination signal, sis- $a$, a protein-coding gene like $s i s-b$, perhaps encoding yet another bHLH family member? Is sis- $a$ involved in vital processes unrelated to sex determination like so many other genes upstream of $S x l$ ? Does sis-a control $S x l$ expression throughout the embryo, or only over a restricted spatial domain, like runt? How is the timing of sis- $a$ expression related to that of other numerator elements, as well as that of the sexdetermination target $S x l$ ? How does the expression of sis- $a$ in the soma compare with that in the germ line? In this paper we present a molecular characterization of sis- $a$ that addresses these and other questions that are critical for understanding both the mechanistic details of sex determination and the evolutionary origin of the fruit fly sex determination signal.

\section{Results}

Cloning and identification of sis-a by $P$ elementmediated transformation

Extensive genetic mapping placed sis- $a$ at or near the distal breakpoint of $D f(1) N 71$ (Cline 1986). We used P element-mediated transformation to identify genomic clones from this region that were capable of complementing the female-specific lethal effect of the sis- $a^{1}$ mutation. Four different P element constructs $\{\mathrm{A} 1, \mathrm{~A} 3$, A4, A10; Fig. 2) were injected into Drosophila embryos, and multiple lines of each were tested for the ability to complement both the sis- $a^{1}$ mutation and $1(1) 10 B b^{1}$, a lethal <0.01 cM away (locus 14 in Cline 1986). We found that mutations in both genes were fully complemented by single copies of the four transgenes, demonstrating that the two genetic functions were located in the $4.5 \mathrm{~kb}$ common to the four constructs (Fig. 2; Table 1). North- ern blots of early embryonic RNA from this region revealed two non-overlapping transcripts of $\sim 1.1$ and $\sim 0.8$ $\mathrm{kb}$ located close to the ends of the complementing region (Fig. 2). To determine the relationship of these transcripts to sis- $a$ and $1(1) 10 B b$, we engineered frameshift mutations that altered the coding portion of each transcript (see Materials and methods) and introduced the mutant constructs into flies by $\mathrm{P}$ element-mediated transformation (Fig. 2, Table 1). Transgenic lines $(A 10 \mathrm{~m} 1)$, with the mutation affecting the $1.1-\mathrm{kb}$ transcript, provided full sis-a function but failed to complement $1(1) 10 B b^{1}$. In contrast, transgenic lines with the mutation affecting the distal $0.8-\mathrm{kb}$ transcription unit (A10m2) eliminated sis-a function but complemented $1(1) 10 B b^{1}$. Hence, the gene encoding the smaller transcript is sis-a. Moreover, it is distinct from the neighboring gene whose function is required for both sexes. Our analysis of this neighboring gene $1(1) 10 B b$, which is a homolog of G10 of Xenopus (McGrew et al. 1989), will be presented elsewhere.

sis-a appears to encode a transcription factor of the basic leucine zipper class

We sequenced the $4.5-\mathrm{kb}$ genomic region that contains sis- $a$ and 1(1)10Bb, and sequenced a total of eight sis- $a$ cDNA clones from two early embryonic cDNA libraries. All eight cDNAs are collinear with the genomic DNA sequence: There are no introns (Fig. 3). Three independent sis-a cDNAs were judged to be full length for the following reasons: First, the size [785 nucleotides without the poly(A) tail] is consistent with that predicted from Northern blots. Second, the $5^{\prime}$ end of each cDNA begins 26 nucleotides downstream of a consensus TATAAA sequence and is preceded by a noncoded $G$ residue (thought to indicate copying of the 5' cap by reverse transcriptase). Finally, in RNase protection experiments, in vitro cDNA transcripts protected the same sized probe fragment as did in vivo mRNA /data not shown).
Figure 2. Genomic DNA tested for sis- $a$ function. A genomic restriction map of a $12-\mathrm{kb}$ region around sis- $a$ is shown. The centromere distal end is to the left. HindIII (H), NheI (N), XhoI (X), SacII (S), MluI (M), and NotI $(\mathrm{Nt})$ sites are marked. The $D f(1) N 71$ distal breakpoint is located between 1.1 and $3.7 \mathrm{~kb}$ from the left end of the map. The locations of the $0.8-\mathrm{kb}$ sis-a and the $1.1-\mathrm{kb} 1(1) 10 B b$ transcripts are shown. The genomic fragments used for P-element-mediated transformation are diagramed below the map. The frameshift mutations in $P\left[A 10 \mathrm{~m} 1\left(w^{+}\right)\right]$and $P\left[A 10 \mathrm{~m} 2\left(\mathrm{w}^{+}\right)\right]$are marked by $\mathrm{X}^{\prime} \mathrm{s}$.
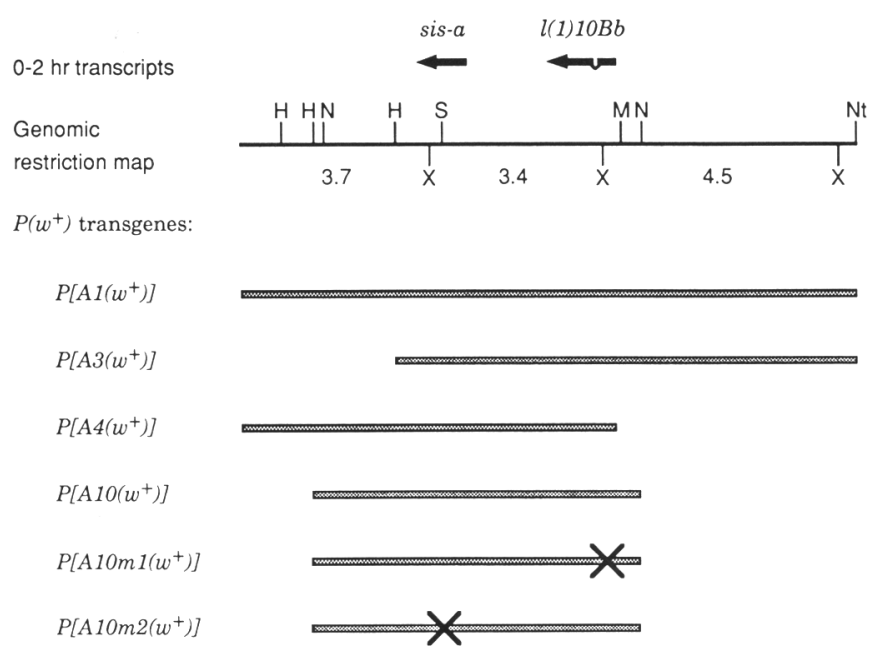

Complementation:

$\begin{array}{cc}\text { sis- } a & l(1) 10 B b \\ + & + \\ + & + \\ + & + \\ + & + \\ + & - \\ - & +\end{array}$


Table 1. Complementation of sis-a ${ }^{1}$ mutant females by single copies of P-element transgenes

\begin{tabular}{|c|c|c|c|c|c|c|c|}
\hline \multirow[b]{2}{*}{$\begin{array}{l}\text { Level of } \\
\text { complementation }\end{array}$} & \multicolumn{7}{|c|}{ Number of transgenic $P\left(w^{+}\right.$, sis-a) lines complementing sis- $a^{1} /$ sis-a $a^{1}$ females } \\
\hline & $P[A 1]$ & $P[A 3]$ & $P[A 4]$ & $P[A 10]$ & $\begin{array}{l}P[A 10 m 1] \\
l(1) 10 B b(f s)\end{array}$ & $\begin{array}{l}P[A 10 \mathrm{~m} 2] \\
\text { sis-a(fs) }\end{array}$ & $\begin{array}{l}P[A 10 \mathrm{~m} 3] \\
\mathrm{ATG} \rightarrow \mathrm{CTG}\end{array}$ \\
\hline Full & 21 & 5 & 4 & 5 & 7 & - & 2 \\
\hline Partial & - & - & 1 & - & - & - & 3 \\
\hline None & - & - & - & - & - & 5 & - \\
\hline
\end{tabular}

Female viability was $25 \%, 50 \%$ and $75 \%$ for the three partially complementing $P[A 10 \mathrm{~m} 3]$ lines and $70 \%$ for the defective $P[A 4]$ line. Crosses were of the form $y w$ sis-a/Binsinscy $q$ o $\times$ y $w$ sis- $a / \mathrm{Y} ; P\left(w^{+}\right.$, sis-a $) /+\delta^{+}$at $25^{\circ} \mathrm{C}$.

Complementation was scored as viability of $y w$ sis- $a^{1} / y w$ sis- $a^{1} ; P\left(w^{+}\right.$, sis-a $) /+$females relative to their y $w$ sis-a/Binsinscy; $P\left(w^{+}\right.$, sis-a)/ + sisters.

The predicted Sis-a protein begins at the first AUG in the mRNA and extends for 189 amino acids. There is a second potential start codon located 45 nucleotides downstream of the first. To determine whether the first AUG is the site of translation initiation, we changed this codon to CUG in the $P[A 10]$ vector, creating $P[A 10 \mathrm{~m} 3]$, and introduced this mutant construct into flies. Single copies of two of the five lines isolated fully complemented sis- $a$ mutant females, but the other three lines were reduced significantly in their ability to provide sis$a^{+}$function (Table 1). We believe that this reduction in sis-a complementation is a consequence of the mutation rather than the sites of insertion of the constructs, because of 36 independent nonmutated lines derived from the constructs shown in Figure 2, only one showed reduced rescue of sis-a $(70 \%$ rescue). Because the loss of the first potential initiation codon reduced, but did not eliminate, sis- $a^{+}$activity, we conclude that the 189amino-acid form is the wild-type Sis-a protein but that its first 15 amino acids are not absolutely required for sis- $a^{+}$function.

The predicted $21-\mathrm{kD}$ Sis-a protein is highly charged and basic (predicted $\mathrm{pI}=9.5$ ). A striking run of six consecutive Gly-Ser repeats near the middle of the protein might serve as a structural hinge. The carboxy-terminal portion of the sequence is similar to the basic leucine zipper (bZIP) class of transcription factors (Vinson et al. 1989) (Fig. 4). bZIP proteins are defined by a characteristic basic DNA-binding motif and a heptad repeat of leucine (or other hydrophobic) residues that form a helical coiled-coil structure mediating dimerization (Landshulz et al. 1989; O'Shea et al. 1991; Ellenberger et al. 1992). The predicted basic DNA-binding region of Sis-a protein shares the invariant asparagine and arginine residues but lacks the characteristic pair of alanines. The mutation in the defective allele, sis- $a^{1}$, that greatly reduces but does not eliminate function, changes Lys to Glu in a moderately conserved position of the DNA-binding motif (Figs. $3,4)$. The putative leucine zipper of Sis-a contains a tetraheptad repeat with three leucines and one isoleucine at the " $d$ " position of the helix. It differs from a canonical coiled-coil sequence at the " $a$ " position, which is occupied by small or hydrophilic residues rather than large hydrophobic ones. Nevertheless, these residues are compatible with a helical structure, and a number of coiledcoil proteins do contain small or charged residues in the a position (Lupas et al. 1991). The " $\mathrm{e}$ " and " $\mathrm{g}$ " positions of bZIP proteins often form interhelical salt bridges that


sis-a $a^{1}$ mutation is an $\mathrm{A} \rightarrow \mathrm{G}(\mathrm{K} \rightarrow \mathrm{E})$ change at nucleotide 547 . cDNA polymorphisms in the $M$. Noll library are $\mathrm{T} \rightarrow \mathrm{G}(\mathrm{D} \rightarrow \mathrm{E})$ at 686 , $\mathrm{A} \rightarrow \mathrm{G}$ (silent) at $720, \mathrm{~T} \rightarrow \mathrm{A}$ at 798 , and a 3-bp (CTT) deletion at 812-814. cDNAs from both libraries contained 11 instead of $12 \mathrm{~T}$ residues from $800-811$.
Figure 3. Sequence of the sis-a gene. The nucleotide and predicted amino acid sequences of sis- $a$ are shown. The TATA box, mRNA initiation site, and poly(A) addition signals are shown against a black background. The cDNAs extended from the +1 position at nucleotide 100 through the poly(A) sequence that begins after the $\mathrm{G}$ residue at nucleotide 881 . The predicted molecular mass of the Sis-a protein is 21,275 daltons. The four hydrophobic repeat residues of the putative leucine zipper motif are circled. The location of the sis- $a^{1}$ mutation is underlined, and the affected amino acid is shown white on black. Identified sequence polymorphisms are underlined, as are the affected amino acids. The 
Figure 4. sis- $a$ encodes a protein of the bZIP class of transcription factors. The sequence of the presumed bZIP motif of Sis-a is compared with a variety of bZIP proteins including six Drosophila sequences. Highly conserved amino acids among the bZIP proteins (including the invariant Asn and Arg residues) are shown against a black background. In the consensus sequence, $B$ designates either Lys or Arg. The Lys residue that is changed to Glu by the sis- $a^{1}$ muta-


tion is marked by the asterisk $\left.\right|^{*} \mid$. The alphabetic designations $|a-g|$ of the positions in the heptad repeats are shown above the sequences.

define dimerization specificities (O'Shea et al. 1992; Vinson et al. 1993). Sis-a is predicted to have only a limited ability to form such salt bridges. That fact, combined with the atypical sequence at the a positions, suggests that Sis-a may have a novel dimerization partner. In common with many transcriptional activators, the amino terminus of Sis-a is rich in acidic, Ser, Gln, and Pro residues.

\section{sis-a activates Sxl in all parts of the embryo}

Although all female somatic nuclei activate $S x l_{P e}$ in response to the diplo-X dose of numerator elements, there are regional differences in the sensitivity of cells to perturbations in individual genes that contribute to the sexdetermination signal (Bopp et al. 1991; Keyes et al. 1992). To determine whether the bZIP protein encoded by sis-a is necessary for the activation of $S x l_{P e}$ in all or only in a subset of nuclei, we examined the effect of the sis- $a^{1}$ mutation on the expression of $\beta$-galactosidase from a $S x l_{P e}-1 a c Z$ fusion (Keyes et al. 1992).

We stained 429 progeny of a cross between sis- $a^{1} /+$ females and sis- $a^{1} / Y$ males, all homozygous for a $P\left[S x l_{P e}-l a c Z^{+}\right]$reporter construct. Three staining classes of 3- to 5-hr-old embryos were observed in the following proportions: $26 \%$ had the strong, relatively uniform $\beta$-galactosidase-staining characteristic of wildtype females; $66 \%$ resembled wild-type males in failing to activate the $S x l_{P e}-1 a c Z$ fusion in any cells; and $8 \%$ stained weakly, with $\beta$-galactosidase present only in the posterior of the embryos. Assuming that the male progeny, which never stain, accounted for $215(50 \%$ of 429$)$ of the 283 unstained embryos, we estimate that the sis- $a^{1}$ mutation prevented the expression of the $S x 1_{P e}-l a c Z$ fusion in two-thirds of the homozygous sis-a mutant female embryos and greatly reduced its expression in the remainder. Thus, like sis- $b$, but unlike runt, sis- $a$ appears to be required in all somatic nuclei for the proper activation of $S x 1$.

The female dose of the sisterless genes causes malespecific lethality

A key aspect of the genetic characterization of the Drosophila sex-determination signal was the demonstra- tion that increasing simultaneously the dose of sis- $a^{+}$ and $s i s-b^{+}$to the normal female value can kill chromosomal (haplo-X) males by causing them to activate $S x l$. These studies were complicated because chromosomal rearrangements were used (duplications) that necessarily altered the dose of a large number of genes besides sis-a and $s i s-b$. The fact that a null $S_{x} l$ allele did not fully rescue males from this "double-sis ${ }^{+}$-duplication" effect was attributed to a nonspecific effect of aneuploidy caused by the chromosomal duplications, rather than to the possible existence of additional vital targets of the sex-determination signal besides Sxl (Cline 1988). The availability of $\mathrm{sis}^{+}$transgenes now allows the manipulation of sis $^{+}$gene dose without changing simultaneously the dose of many other genes unrelated to sex determination; consequently, we can test whether a mere doubling of the dose of sis-a $a^{+}$and sis- $b^{+}$in males can lead to lethality and whether such lethality is the result of ectopic activation of $S x l$ alone. Toward this end, we examined the effects of $10.5-\mathrm{kb} P\left(\right.$ sis- $\left.b^{+}\right)$duplications generated earlier (Erickson and Cline 1991) in combination with the newly isolated $12-\mathrm{kb} P\left(s i s-a^{+}\right)$transgenes.

A double-sis ${ }^{+}$-duplication second chromosome carrying one $s i s-b^{+}$and one sis- $a^{+}$transgene showed the dominant, male-specific, cold-sensitive lethality found previously for a second chromosome carrying enormously larger X-chromosomal duplications of these two genes. As in earlier experiments, male survival was influenced by the genetic background. It ranged from a low of $<0.3 \%$ in a cross to a $y w$ stock to a high of $15 \%$ in a $W^{1118}$ stock at $18^{\circ} \mathrm{C}$ (see Genetic analysis in Materials and methods). Moreover, as had been the case with the chromosomal duplications, escaper males were generally sterile and often $(33 \%)$ displayed a characteristic phenotype: missing external genitalia and analia. As expected, females were unaffected by the transgene-bearing second chromosome.

Data in Table 2 show that for the transgene duplications, the male-lethal effects of increased $\mathrm{sis}^{+}$dose were suppressed completely by a $S x l$ null mutation, even when the $\operatorname{sis}^{+}$dose was increased above the normal female value. In these crosses, an X-linked $P\left(s i s-b^{+}\right) \mathrm{du}-$ plication was included in addition to a variety of different double-sis ${ }^{+}$-duplication second chromosomes; 


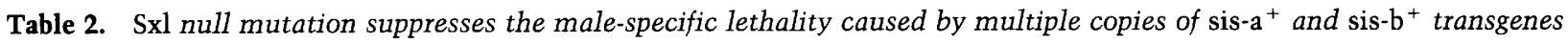

\begin{tabular}{|c|c|c|c|c|}
\hline \multirow[b]{3}{*}{$P\left(\right.$ sis $\left.^{+}\right)$duplications $(=P P)$} & \multicolumn{4}{|c|}{ Number of males recovered ${ }^{a}$} \\
\hline & \multicolumn{2}{|c|}{$S x 1^{+} P\left(\right.$ sis $\left.-b^{+}\right)$} & \multicolumn{2}{|c|}{$S x l^{-} P\left(\right.$ sis- $\left.b^{+}\right)$} \\
\hline & $P P /++$ & $++/ \mathrm{CyO}$ & $P P /++$ & $++/ \mathrm{CyO}$ \\
\hline$P\left[A 1\left(\right.\right.$ sis $\left.\left.-a^{+}\right)\right] 5+P\left[A 1\left(\right.\right.$ sis $\left.\left.-a^{+}\right)\right] 2$ & 0 & 124 & 124 & 144 \\
\hline$P\left[A 1\left(\right.\right.$ sis- $\left.\left.a^{+}\right)\right] 89+P\left[A 1\left(\right.\right.$ sis $\left.\left.-a^{+}\right)\right] 1$ & 0 & 93 & 95 & 93 \\
\hline$P\left[A 1\left(\right.\right.$ sis $\left.\left.-a^{+}\right)\right] 4+P\left[B 5\left(\right.\right.$ sis $\left.\left.-b^{+}\right)\right] 22$ & 0 & 139 & 134 & 131 \\
\hline$P\left[A 1\left(\right.\right.$ sis $\left.\left.-a^{+}\right)\right] 6+P\left[B 5\left(\right.\right.$ sis $\left.\left.-b^{+}\right)\right] 3$ & 0 & 91 & 113 & 97 \\
\hline
\end{tabular}

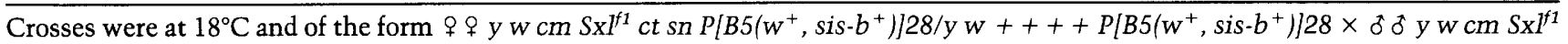
$c t / Y ; P\left(w^{+}, s i s^{+}\right) P\left(w^{+}\right.$, sis $\left.{ }^{+}\right) / C y O$. A $1: 1: 1: 1$ ratio of progeny is expected in the absence of lethal effects.

${ }^{a}$ Only males nonrecombinant for the $\mathrm{cm}-c t$ interval $(1.1 \mathrm{~cm})$ are recorded.

therefore, the experimental males carried either two extra doses of sis-a $a^{+}$and one extra sis- $b^{+}$or one extra sis $-a^{+}$and two extra sis- $b^{+}$. Even with these three extra doses of $\mathrm{sis}^{+}$, and even at low (least permissive) temperature, males with no functional $S x l$ gene were fully viable, in contrast with their $S x l^{+}$brothers who invariably died. These results argue strongly that $S x l$ is the only significant target of the somatic sex-determination signal.

\section{Duplications of sis-a ${ }^{+}$and sis- $\mathrm{b}^{+}$are not sufficient to activate $\mathrm{Sxl}_{P e}$ to the female level in all tissues}

To what extent does doubling the dose of just the two strongest numerator elements, sis- $a$ and sis- $b$, in animals with one $\mathrm{X}$ chromosome, mimic the effects on the $S \mathrm{X} l$ establishment promoter of doubling the number of entire $\mathrm{X}$ chromosomes? To address this question we examined the progeny of a cross between females homozygous for the $S x l_{P e}-l a c Z$ fusion and $S x 1^{-}$males carrying one copy of a double-sis ${ }^{+}$-duplication second chromosome. Under the conditions used, $12 \%$ of the double duplication males survived to adulthood (but were sterile). The abnormal pattern of $\beta$-galactosidase expression (Fig. $5 \mathrm{~B}$ ) easily distinguished sons carrying the two extra copies of $\mathrm{sis}^{+}$from both of their sisters (Fig. 5C) and their nonduplication brothers (Fig. 5A). These male embryos expressed little or no $\beta$-galactosidase anteriorly but produced levels of $\beta$-galactosidase that were often at, or near, the female level in the posterior. This posterior bias in the activation of the $S x l_{P e}$ reporter construct by extra copies of the sis genes in males is reminiscent of the posterior bias in residual expression of $S x l_{P e}-l a c Z$ for females who are homozygous for sis- $a^{1}$.

\section{Like sis-b, sis-a is one of the first genes}

to be transcribed in the embryo; unlike sis-b, sis-a is not expressed in somatic cells at later stages

The developmental profile of sis-a mRNA was determined using RNase protection assays (Fig. 6). The other major numerator element, sis-b, is included for comparison. We found that sis- $a$ and sis- $b$ were expressed zygotically at the earliest time point examined, $0-2 \mathrm{hr}$ after fertilization. The absence of these transcripts from adult females (and the results of in situ hybridizations; see below) established that these early transcripts were zy-

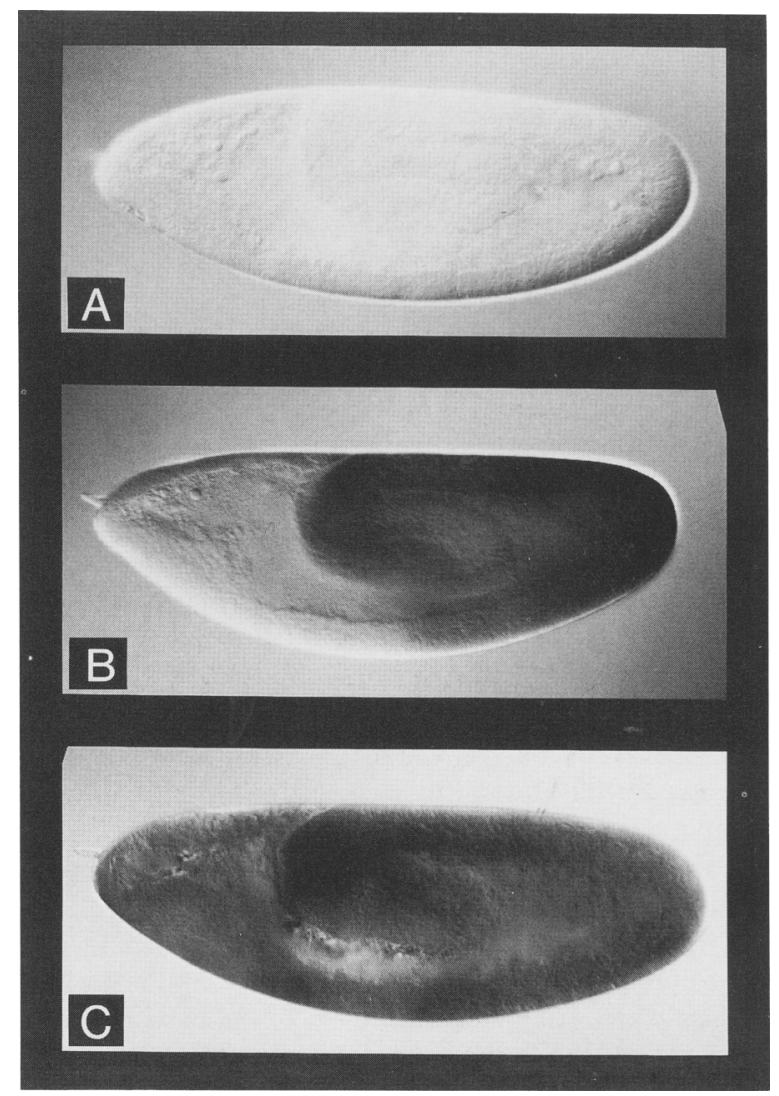

Figure 5. Duplication of sis- $a^{+}$and $s i s-b^{+}$causes ectopic activation of $S x l_{P e}$ in X/Y embryos. Embryos with one copy of a $S \mathrm{X} l_{P e}-l a c Z$ fusion were fixed and stained with X-gal. $(A)$ Normal $\mathrm{X} / \mathrm{Y}$ male embryo. (B) X/Y embryos with a sis- $a^{+}$, sis- $b^{+}$double duplication. (C) Female X/X embryo. Embryos were the progeny of a cross between $y w / y w$ females homozygous for $S x l_{P e}-l a c Z$, and $y \mathrm{w} \mathrm{cm} \mathrm{Sxl} \mathrm{I}^{f 1} \mathrm{ct} / \mathrm{Y} ; P\left[A 1\left(\mathrm{w}^{+}\right.\right.$, sis- $\left.\left.a^{+}\right)\right] 4, P\left[B 5\left(\mathrm{w}^{+}\right.\right.$, sis$\left.\left.b^{+}\right)\right] 22 / C y O$ males. Of 465 embryos scored, 122 were unstained, 110 exhibited nonuniform staining similar to that in $B$, and 233 stained relatively uniformily as in $C$. 



Figure 6. Developmental profile of sis- $a$ expression. RNase protection was used to monitor the amount of sis- $a$ and sis- $b$ mRNAs at the indicated stages. The sis- $a$, sis-b, and $r p 49$ hybridizations each contained $\sim 0.4,0.8$, and $0.05 \mu \mathrm{g}$ poly $(\mathrm{A})^{+}$ RNA. Preadult RNA samples were from mixed sex populations.

gotic and not maternal in origin. Both mRNA species increased in amount during the 2- to 4-hr period and remained relatively constant through the first half of embryonic development. They disappeared $\sim 10-12 \mathrm{hr}$ after fertilization. scute (sis-b) mRNA reappeared in the thirdinstar and pupal collections, consistent with its proneural function in imaginal discs. In contrast, sis-a did not appear to be expressed after the first half of embryogenesis.

A much closer examination of sis gene expression was made by in situ RNA hybridization during the period of early embryogenesis when the sex-specific expression of Sxl is set by the X-chromosome dose. This study also included a parallel examination of expression from the sex-determination signal target $S x l$. This detailed analysis showed that the differences in expression between sis- $a$ and sis- $b$ are far greater than had been suggested by RNA analysis on whole embryo homogenates. The early fly embryo is characterized by a series of rapid nuclear divisions that occur in the interior of the fertilized egg (Poulson 1950; Sonnenblick 1950; Foe and Alberts 1983). After the sixth nuclear division cycle, most of the nuclei begin a stepwise migration to the periphery to form the syncytial blastoderm $1 \mathrm{~min}$ into cycle 10 . The first nuclei to reach the surface bud off and form the pole cells, which are the precursors to the germ cells of the fly. The somatic nuclei divide three more times at the surface before cellularization during cycle 14 . The nuclei that remain behind in the center of the embryo cease to divide after cycle 10 and become polyploid. These polyploid yolk nuclei are believed to be involved in the utilization of the egg yolk and make no direct contribution to the structure or tissues of the embryo. Limited zygotic



Figure 7. In situ hybridization to sis-a transcripts in wholemount embryos. Wild-type embryos were prepared and hybridized with a digoxygenin-labeled antisense RNA probe to detect sis-a mRNA. Embryos at nuclear cycles $5,8,10,12$, and 14 and during germ band extension (gbe) are shown. Precellular embryos were staged as described in Materials and methods. sis- $a$ expression was first detected in cycle 8 . The cycle 8 embryo is overstained relative to the others to emphasize the onset of sis-a transcription. The intense staining in later embryos represents expression from the polyploid yolk nuclei. 
transcription is generally thought to begin as the nuclei reach the periphery, with the bulk of the zygotically expressed genes becoming active during cellularization (Lamb and Laird 1976; Zalokar 1976; Anderson and Lengyel 1979|.

sis- $a$ transcripts were first clearly detected at the end of the eighth nuclear cycle just before to the arrival of the pole cell nuclei at the surface of the embryo (Fig 7). Initially, all of the embryonic nuclei expressed sis- $a$ mRNA; however, as the pole buds formed during cycle 9, sis- $a$ expression was extinguished in the prepole cell nuclei. The sis-a mRNA was not freely diffusible during these early cycles. It appeared to be associated closely with the somatic and yolk nuclei through nuclear cycle 10. By nuclear cycle 12, however, the sis-a transcripts were distributed relatively uniformly in the somatic (peripheral) portion of the embryo and were no longer associated with the nuclei. The sis- $a$ mRNA reached its maximum level during late cycle 12 and early cycle 13 and decayed rapidly thereafter; therefore, by early cycle 14 , when somatic cells first begin to form in the embryo, there was very little sis-a mRNA at the periphery. This condition persisted after cellularization, indicating that there is little or no expression of sis- $a$ in either the somatic or the germ cells of the embryo.

In contrast with the somatic nuclei, which expressed little or no sis- $a$ after cycle 14, the yolk nuclei accumulated high levels of sis-a mRNA from cycle 8 until they degenerated some $10-11 \mathrm{hr}$ after fertilization. The
mRNA produced from the yolk nuclei did not diffuse throughout the yolk but, instead, appeared to be associated with the "islands of cytoplasm" that have been reported to surround the yolk nuclei (Poulson 1950; Sonnenblick 1950|.

The expression of sis- $b$ in the peripheral portion of early embryos was very similar to that seen for sis-a; moreover, sis- $b$ was also expressed only in somatic nuclei. We could first reliably detect sis-b mRNA at cycle 9. As with sis- $a$, the earliest sis- $b$ transcripts were distributed nonuniformly, maintaining an association with the nuclei through cycles 9 and 10 . The sis- $b$ mRNA increased in amount and became uniformly distributed during cycle 11 and peaked abruptly in cycle 12 (Fig. 8). The peak was followed by a rapid decay; therefore, by early cycle 14 we could detect only traces of sis-b mRNA. At the end of cycle 14 and subsequently during gastrulation, the proneural scute pattern of expression developed. In contrast with sis- $a$ there was no strong $s i s-b$ expression in the yolk nuclei.

The importance of this early sis-b expression was demonstrated by the remarkable coincidence between the time course of sis- $b$ mRNA accumulation and the temperature-sensitive period of the allele $s i s-b^{s c 3-1}$ (Fig. 9). This allele is profoundly temperature sensitive for its sex-determination function but not for the proneural function required for adult bristle development, apparently as a consequence of a defect specifically affecting early expression (Parkhurst et al. 1993; see Genetic anal-
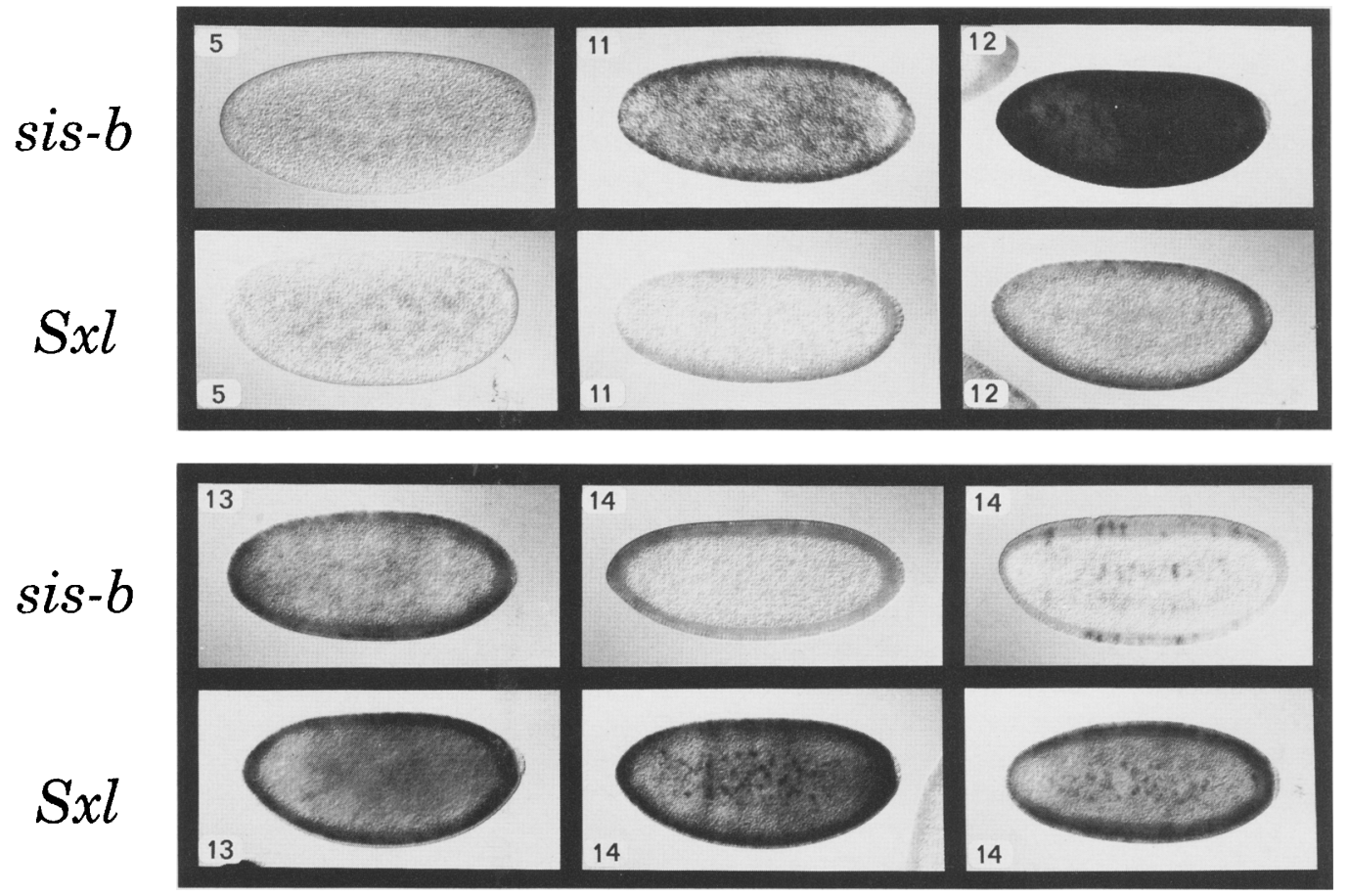

Figure 8. Comparative time course of sis- $b$ and $S x l$ expression in early embryos. Wild-type embryos at nuclear cycles $5,11,12,13$, and 14 (early and late) are shown. Embryos were collected and prepared together and hybridized separately with digoxygenin-labeled RNA probes specific for sis- $b$ or for the embryonic El exon of $S x l$. sis-b expression was first apparent at cycle 9 (not shown). The striped staining in the late cycle 14 embryo is the scute pattern of expression and is unrelated to sex determination. The sis-b-stained embryos represent the darkest staining class at each cycle and are presumed to be female. Only female embryos stained with the Sxl probe. 




Figure 9. A brief, very early temperature-sensitive period for sis- $b^{s c 3-1}$ females. The viability of sis- $b^{s c 3-1}$ homozygous females was compared with that of their fully viable, hemizygous $s i s-b^{s c 3-1} / Y$ brothers as a function of temperature. The age of the embryos at the moment of the temperature shift is indicted in hours after oviposition. The abscissa scale has been adjusted for the fact that development is approximately twice as fast at $29^{\circ}$ as at $18^{\circ} \mathrm{C}$. Number of males scored for the time points are $29 \rightarrow 18^{\circ}: 521,174,167,467,516,356,1060 ; 18 \rightarrow 29^{\circ}: 792,427$, $130,181,275,375,194$ (for details, see Materials and methods).

ysis in Materials and methods). It behaves as a strong female-specific lethal at the nonpermissive temperature $\left(29^{\circ} \mathrm{C}\right)$ and has no effect on viability at $18^{\circ} \mathrm{C}$ (Erickson and Cline 1991; Torres and Sanchez 1991). The experiment of Figure 9 shows that $s i s-b$ expression is important for female development only between 1 and $2.5 \mathrm{hr}$ after fertilization (corresponding to nuclear cycles 9 through early 14 ), with the most sensitive period being between 1.5 and $2 \mathrm{hr}$ postfertilization (cycles 12 and 13).

sisterless transcript levels appear to be proportional to gene dose

At what level does the signal amplification occur that is responsible for the remarkably nonlinear response of $\mathrm{Sxl}$ to the dose of the sisterless genes? Our in situ RNA hybridization results suggest that it must occur after sis gene transcription. We were able to discern small differences in staining intensity between embryos at the same stage of development throughout the period when the sis genes were expressed, but in most cases it was impossible to classify reliably the embryos as belonging to the lighter or darker staining classes. However, in late cycle 12 , when the sis mRNA levels peaked, we could distinguish approximately equal numbers of lighter and darker stained embryos that appeared subjectively to differ by about twofold in staining intensity. Given the rapid changes in mRNA levels and the quantitative limitations of the technique, we cannot be certain that the lighter embryos were the one-dose males and the darker embryos the two-dose females, but the equal numbers in the two staining classes is suggestive.

\section{The Sxl establishment promoter becomes active as sis gene expression peaks}

The first description of early $S x l$ transcription indicated that $S x l_{P e}$-derived transcripts could be detected first at cycle 9 , peaked in cycle 12 , and declined to low levels by the end of cycle 14 (Keyes et al. 1992). We found it difficult to reconcile those results with our data for the timing of sis- $a$ and sis- $b$ expression and with the result that runt mRNA first appears around cycle 12 (M. Klingler and P. Gergen, pers. comm.). For this reason, we reexamined the time-course of expression from $S x l_{P e}$ using precisely the same conditions that we used to examine sisterless gene expression. In contrast with the earlier report, we detected SxI expression first in cycle $12 \mathrm{em}$ bryos, the stage at which the sis- $a$ and sis- $b$ mRNAs were near their maximum levels. Sxl mRNA increased in abundance in female embryos during cycles 13 and 14, reaching peak levels early in cycle 14. By the end of cycle 14 the transcripts from $P e$ began to decay, leaving only low levels of $S x l_{P e}$ mRNA that persisted into the early germ band-extended embryos. In the cycle 12 embryos much of the staining was apparent as two tiny dots in the somatic nuclei (only the female embryos stained with the $S x l_{P e}$ probes). These nuclear dots are thought to represent nascent transcripts and have been observed for a number of genes (Shermoen and O'Farrell 1991). We did not observe such putative nascent transcripts for sis-a, perhaps because of the much smaller size of the primary transcript $(0.8$ vs. $8.5-16 \mathrm{~kb})$. The $S \times l$ transcripts were present both in the cytoplasm and as nuclear dots in cycle 13 embryos, indicating that the gene was actively transcribed at that time. The Sxl transcripts appeared to be entirely cytoplasmic by early cycle 14 , indicating that $S x l_{P e}$ was no longer active.

\section{Discussion}

One of the first things that a Drosophila embryo does is determine its sex by counting its X chromosomes. This urgency may reflect the importance of achieving $\mathrm{X}$-linked gene dosage compensation as soon as zygotic gene expression commences in earnest at the cellular 
blastoderm stage. The earliest manifestation of sex determination is the transcriptional activation of the female-specific Sex-lethal gene by the action of a diplo-X dose of X-linked numerator elements that include the sisterless genes. The molecular characterization of sis- $a$ allows comparisons to be made between this X/A numerator element and sis- $b$, the other major numerator element whose molecular nature is known. These comparisons provide new insights into the general features of the Drosophila sex-determination signal and the mechanism by which it acts. Perhaps the most important simplifying result is that like sis- $b$, sis- $a$ functions as part of the sex-determination signal by virtue of the protein product it encodes. Moreover, that protein product appears to be a member of a family of DNA-binding transcription factors, although not the same family in which the $s i s-b$ gene product belongs.

\section{Major numerator element genes are expressed early, but only in somatic nuclei}

In situ RNA hybridization results reported here show that the somatic expression of both sis- $a$ and sis- $b$ begins at nuclear cycles $8-9$, before the point when cleavage stage nuclei have reached the periphery of the egg, and that expression peaks late in nuclear cycle 12 . The time course of sis- $a$ transcription during this early period is very similar to that of sis- $b$, suggesting that their gene products act directly on $S x l$ and not in a cascade with one sisterless gene acting on another. Analysis of sisterless gene transcription in sis null mutant embryos will be required to establish this point.

Our results for the onset of sis-b expression differ in some respects from those presented by Parkhurst et al. (1993). They reported that sis-b expression begins in cycle 3 and that the early transcripts are uniformly distributed throughout the embryo. This would represent the earliest zygotic expression of any wild-type gene in Drosophila. In contrast, we found that embryos from cycles 1 to 7 were not distinguishable from one another in staining intensity. Moreover, we found that like the earliest sis- $a$ transcripts, the earliest $s i s-b$ mRNAs were closely associated with the embryonic nuclei during cycles 9 and 10, a pattern of mRNA localization observed for many early expressed genes in Drosophila (Pignoni et al. 1992; D. Pritchard and G. Schubiger, pers. comm.). The increase in $s i s-b$ mRNA concentration from cycle 3 to 12 reported by Parkhurst et al. (1993) is modest considering that the number of nuclei increase $\sim 500$-fold during this period. In contrast, we observed an abrupt and dramatic increase in sis- $b$ mRNA levels during cycles 9-12, which appears more consistent with the exponential increase in nuclear number that occurs during this time.

Whatever the explanation for these discrepancies, the sharp temperature-sensitive period (TSP) for $s i s-b^{s c 3-1}$ suggests that regardless of when sis- $b$ transcription is initiated, it only becomes important for sex determination after nuclear cycle 9 . The sis- $b^{\text {sc3-1 }}$ TSP begins in cycle 9 and ends by cycle 14, with the most sensitive period occurring during the time that both we and Parkhurst et al. (1993) observed maximum levels of sis-b mRNA. The onset of the TSP was particularly clear. Diplo-X embryos shifted down to the permissive temperature between 0 and $60 \mathrm{~min}$ after egg deposition were perfectly viable, and even those shifted at 60-90 min (cycles 8-11) were only slightly less viable than their control siblings. Still longer exposures at the nonpermissive temperature caused dramatic reductions in female viability. The near perfect coincidence between the sis- $b$ TSP and expression results reported here establish the functional importance of this early burst of $s i s-b$ expression. These results are consistent with an earlier TSP determination of what is surely a related dominant lethal effect of sis- $b^{s c 3-1}$ in females that are heterozygous for $\mathrm{Sxl}^{-}$(Torres and Sanchez 1991).

Expression of the sisterless genes preceded the expression of their target, $S x l$, by about three cell cycles: We first detected $S x l$ transcripts at cycle 12 near the time that the sis mRNA levels peaked. This onset is somewhat later for $S x l$ transcription than was reported by Keyes et al. (1992). The basis for this discrepancy is not clear. It could reflect differences between the fly stocks used or differences in the criteria used to stage early embryos. Our embryo preparations were stained with DAPI so that number and density of nuclei could be determined readily, whereas Keyes et al. (1992) relied on the appearance of pole cells in embryos that had been heavily proteolyzed. It seems unlikely that the discrepancies were caused by sensitivity differences, as both the onset of $S x l$ transcription and the peak of mRNA accumulation in our experiments were shifted relative to those reported by Keyes et al. (1992). In any event, the present result is more consistent with expectations based on the study of the two sis genes that was done in parallel on the same collections of embryos.

It was reported earlier that $S x l_{P e}$ is never active in germ cells (Keyes et al. 1992). The in situ RNA analysis that we report here suggests why this might be. The first nuclei to reach the cortex form the pole cells that establish the germ line of the organism. Although sis- $a$ transcription begins in cleavage-stage nuclei before the nuclei have reached the egg cortex, sis-a expression is extinguished when they do arrive to bud off as pole cells. In contrast, when the rest of the nuclei reach the cortex at the beginning of cycle 10, they continue to express sis-a for some time. The same appears to be true for sis- $b$, but because its mRNA appears to be expressed slightly later and is not as localized as that from sis-a, the shutoff as pole cells form is not as striking. It remains to be determined whether it is the shutoff of numerator element expression per se that is responsible for the lack of activation of $S \mathrm{I}_{P e}$ in diplo-X pole cells and whether that shutoff is the active consequence of an inhibitor in the pole plasm or a passive consequence of the lack of an activator in this specialized cytoplasm.

sis-a activates Sxl transcription in all somatic cells

Because all somatic cells determine their sex in response 
to the dose of $\mathrm{X}$ chromosomes, one might have thought that numerator elements affect $S x l$ expression in all nuclei. Such an expectation was met by sis-b (Bopp et al. 1991). The results with the weaker numerator element, runt, however, gave a surprisingly different result (Duffy and Gergen 1991). Null mutations only affected Sxl expression over the central region of the embryo and, even then, did not invariably abolish $S x l$ expression within this domain, consistent with this gene's participation in the sex-determination process somewhat less central.

Using a $S x l_{P e}-l a c Z$ reporter construct, we show here that the strong numerator element sis-a behaves like the strong element sis- $b$ in affecting $S x l$ expression throughout the embryo. Even with the non-null sis- $a^{1}$ allele, expression of $S x l_{P e}$ was abolished in the majority of homozygous mutant female embryos.

\section{Developmental specificity of sis-a and its potential implications for Sxl regulation}

To understand how genetic elements that participate in the sex-determination signal work and how they were recruited during the course of evolution, it is important to determine the extent to which these elements participate in other aspects of development besides sex determination. It is striking that of the six elements of the sex signal that had been characterized previously at the molecular level, only $S x l$ is truly sex specific in its function. The molecular characterization of sis-a presented here suggests that the only essential function of sis- $a$ may be its role in sex determination. The mutant lesion responsible for the female-lethal phenotype of sis- $a$ is shown to be a missense change that affects a residue in the conserved DNA-binding domain of this bZIP protein. This is not the kind of lesion one would expect to differentially affect the functions of a multifunctional protein product if these functions all involve DNA binding. Unlike the other molecularly characterized elements of the sex signal, sis-a expression ceases before the nuclei of the young embryo become cellularized. The only sis-a expression that continues after the somatic activity state of Sxl has been determined is in the yolk nuclei. These nuclei are atypical: They never migrate to the egg cortex, and they degenerate midway through embryogenesis without becoming cellularized. It is not known whether they are necessary for development, or what their function might be. If sis- $a$ has a non-sex-specific function, it is most likely to involve the yolk nuclei. Indeed it may be that sis- $a$ was recruited as part of the sex-determination signal during evolution because it already had a very early function in yolk utilization.

The temporal and spatial specificity of sis- $a$ expression may be responsible for the timely shutoff of $S x l_{P e}$ that is critical for the proper operation of the sex-determination signal. The other known components of the sex signal are expressed at later stages and become dosage compensated in connection with their other functions in development. If $S x l_{P e}$ were to remain responsive to the numerators after the onset of dosage compensation, at least some male cells would be in danger of inappropriately expressing $S x l_{P e}$. The fact that sis- $a$ transcripts disappear just as $S x l_{P e}$ shuts off raises the possibility that it is specifically the lack of Sis-a protein throughout the rest of development that prevents the reactivation of $S x l_{P e}$.

\section{Implications of the sis-a study for the mechanism of X-chromosome counting}

How is the twofold difference in sis gene dose amplified into an all-or-none, switch-like response by $S x l_{P e}$ ? The fact that sis transcript levels are roughly proportional to sis gene dose suggests that amplification is not at the level of sis gene transcription. The timing of sis- $a$ and $s i s-b$ expression suggests that they both act directly at $S x l_{P e}$. Considered in light of the fact that sis- $a$ and $s i s-b$ encode two different categories of transcription factor, this implies that amplification may occur as a consequence of there being qualitatively different sites for different transcriptional activators at $S x l_{P e}$. If each of these different classes of sites were also present in multiple copies, there would be additional opportunities for signal amplification. Herschlag and Johnson (1993) have recently reviewed the variety of ways that multiple transcription factor-binding sites at a regulated promoter can generate nonadditive effects on transcription that might be responsible for establishing sharp response thresholds for developmental signals. There are precedents in Drosophila for the nonlinear response of a developmentally regulated promoter being caused by repeated factorbinding sites, often for different classes of transcription factors (Driever et al. 1989; Struhl et al. 1989; Jiang et al. 1991; Ip et al. 1992a,b; Small et al. 1992; Jiang and Levine 1993).

Opportunities for signal amplification may also be provided by positive and negative interactions among the various subunits of these multimeric regulatory proteins before their interaction with $S x l_{P e}$. It seems likely that the $\mathrm{bHLH}$ proteins Sis-b and Da form heterodimers that bind to and activate $S x l_{P e}$, since this protein heterodimer has been shown to bind DNA efficiently in vitro /Cabrera and Alonzo 1991; Van Doren et al. 1991). On the other hand, since the dose of $d a$ is the same in both sexes, this positive interaction by itself is unlikely to be involved in signal amplification (but see below). The sequence of the putative Sis-a leucine zipper frustrates attempts to predict what its possible dimerization partners might be (O'Shea et al. 1992; Vinson et al. 1993). Moreover, this sequence gives no indication that Sis-a is likely to form functional homodimers that might serve as an amplifying step.

Discrimination between the male and female sis gene doses is likely to involve negative interactions among their subunits before binding at $S x l_{P e}$. The two known negative signal elements, the HLH proteins Emc and Dpn, are believed to prevent or alter the DNA binding of Sis-b by dimerizing with it and preventing its association with Da protein (Van Doren et al. 1991). These or other inhibitory proteins could serve both to set the activation threshold for $S_{x l} l_{P e}$ at an optimum for discrimination and to amplify the relative male/female difference in numer- 
ator products if they sequester proportionately more activator in males than in females (Parkhurst et al. 1990; Parkhurst and Ish-Horowitz 1992; Younger-Shepherd et al. 1992). No analogous candidates for negative leucine zipper partners for Sis-a have been identified. Although such anti-Sis-a zippers may yet be found, it is possible that the HLH inhibitors Emc and Dpn function to partially sequester Sis-a (Bengal et al. 1992), or even that other "nonzipper" proteins sequester or otherwise inhibit Sis-a (Schule et al. 1990; Yang-Yen et al. 1990).

One interesting possibility raised by our analysis of sisterless and $S x l$ expression is that the negative factors, whatever their identity, may not function at the same time. If it is assumed that sis mRNA levels are predictive of Sis protein levels, our data suggest that $S x l_{P e}$ becomes active after a threshold concentration of the Sis proteins is exceeded in females during cycle 12 . Is this initial cycle 12 threshold of Sis protein reached by males as they proceed into cycle 13 , and if so, how do they avoid activating Sxl? Curiously cycle 12 is the point when the denominator (negative) element $d p n$ becomes active in the zygote (Bier et al. 1992; Younger-Shepherd et al. 1992). Perhaps the specific role of zygotic $d p n$ and other denominators is to raise the activation threshold for $S x l_{P e}$ as the levels of Sis protein increase, keeping that threshold above a level that would activate $S x l_{P e}$ in males. With such a model one need not postulate that undetectable levels of $d p n$ expression influence the sexdetermination signal early (Parkhurst and Ish-Horowitz 1992). The initial threshold might be defined primarily by maternally supplied inhibitors such as Emc, with zygotic denominator elements assuming an increasingly important role as development proceeds.

As more information is gained on the nature and function of the maternal and zygotic factors that participate in the regulation of $S x l_{P_{e}}$, the primary event of somatic sex determination, the textbook view of the sex signal as a rather static $\mathrm{X} / \mathrm{A}$ ratio, may outlive its usefulness. The classic work that led to the concept of an X/A ratio did serve to exclude some possible mechanisms for X-chromosome counting, but it also may have caused more attention to be focused on zygotically expressed autosomal genes than will have been warranted. In essence, the sexual development of the fruit fly is determined through the operation of an X-chromosome counting mechanism that functions in a molecular milieu that includes both maternal and zygotic factors. The tools now available should enable rapid progress toward understanding how a simple twofold dose difference in a diverse assembly of $\mathrm{X}$-linked genes that encode transcription factors can be transduced into such a profound difference in developmental fate. How this heterogeneous group of transcription factors came to be recruited for this task is a question of considerable evolutionary interest.

\section{Materials and methods}

DNA analysis and germ-line transformation

DNA manipulations, Southern blots, and dideoxy DNA se- quencing were done by standard methods (Sambrook et al. 1989). Cosmid (pWE15) clones containing Oregon-R DNA from the 10B4- 6 region were generously provided by Richard Binari and Norbert Perrimon (Harvard University, Cambridge, MA). The fragments analyzed by germ-line transformation were cloned into a derivative of the $w^{+}$P-element vector Casper (Pirrotta 1988) in which a NotI site replaced the BamHI site. Transformants were obtained by coinjection with the pTurbo transposase source (provided by R. Steward, Princeton University, NI) using standard techniques (Spradling 1986). The genomic restriction fragments carried by each transformant are $P\left[A 1\left(w^{+}\right.\right.$, sis- $\left.\left.a^{+}\right)\right] 12-\mathrm{kb}$ NotI-Sau3A; $P\left[A 3\left(w^{+}\right.\right.$, sis- $\left.\left.a^{+}\right)\right]$ 9.0-kb NotI-HindIII; P/A4 $\left(\mathrm{w}^{+}\right.$, sis- $\left.\left.a^{+}\right)\right]$7.3-kb Sau3A-MluI; $P\left[A 10\left(\mathrm{w}^{+}\right.\right.$, sis- $\left.\left.a^{+}\right)\right]$and its mutant derivatives $P[A 10 \mathrm{~m} 1]$, $P[A 10 \mathrm{~m} 2]$, and $P[A 10 \mathrm{~m} 3]$ 6.4-kb Nhe1-NheI. Mutations were created in plasmid subclones [pKS $|+|$ Stratagene] and recloned into the larger $P[A 10]$ vector. The 4-bp insertion in $P[A 10 \mathrm{~m} 1]$ was made by filling in an $X$ hoI site resulting in a frameshift after the amino acid 22 of $1(1) 10 B b . P[A 10 \mathrm{~m} 2]$ carried a 2 -bp deletion that alters the sis- $a$ reading frame after the amino acid 96 and was made by blunt ending the SacII site with T4 DNA polymerase. The mutation in $P[A 10 \mathrm{~m} 3]$ that changed the sis- $a$ initiation codon to CUG was introduced using the method of Kunkel (1985) with a mutagenic primer AAAAATCACCCTGGAACGGA. cDNA clones were isolated from the $\lambda \mathrm{gt} 10 \mathrm{E} 6 \mathrm{li}-$ brary (3- to 12-hr embryo) of Poole et al. (1985) and a $\lambda g t 10$ cDNA library (0- to 4-hr embryo) of $\mathrm{M}$. Noll (unpubl.). cDNA inserts were subcloned as EcoRI fragments into pKS| +) (Stratagene) for sequence analysis. For sequence analysis of the sis- $a^{1}$ allele, a 1028-bp fragment was PCR amplified from sis- $a^{1} \mathrm{mu}-$ tant male DNA. Clones from three independent amplifications were sequenced from position -11 to 766 with identical results. The only difference from the wild-type sequence in Figure 3 was the single nucleotide change at position 547.

\section{RNase protection}

Poly $\mid \mathrm{A})^{+}$RNA was prepared (Samuels et al. 1991) from Oregon- $R$ adults, pupae, and staged embryos and larvae. RNase protection experiments were done as described (Sambrook et al. 1989). The 750-nucleotide (EcoRI-SacII) genomic sis- $a$ antisense probe protected the same 352-nucleotide $5^{\prime}$ end fragment with both poly $(\mathrm{A})^{+} \mathrm{RNA}$ and RNA synthesized in vitro from a full-length cDNA template. The sis- $b$ (Villares and Cabrera 1987) and $r p 49$ (O'Connell and Rosbash 1984) probes protected internal fragments of 340 and $\sim 350$ nucleotides. The source of the two bands in the sis-b lanes in Figure 6 is not known. All experiments were confirmed to be in probe excess.

\section{In situ analysis of transcription}

The $P\left(w^{+}, S x l_{P e}-l a c Z^{+}\right)$transgene is similar to that described in Keyes et al. (1992). It carries a 3.7-kb SalI-BglII fragment that ends 44 nucleotides downstream of the start of $S x l$ exon E1 fused to a chimeric $A D H-l a c Z^{+}$open reading frame. $\beta$-Galactosidase was assayed as described (Klämbt et al. 1991). In situ hybridizations and digoxygenin labeling were done using modifications [Harland 1991; G. Panganiban (University of Wisconsin-Madison), pers. comm.] of the procedure of Tautz and Pfeifle (1989). Double-stranded DNA and single-stranded RNA probes containing the entire coding regions were used with similar results for sis-a and sis-b. Sxl expression was examined with RNA probes corresponding to either the embryo-specific first exon (specific for $\mathrm{Sxl}_{\mathrm{Pe}}$-derived transcripts; Keyes et al. 1992) or to a region common to all $S x l$ cDNAs lexons $2,4,5$, and 6; Samuels et al. 1991). Similar results were obtained with both 
probes until late in cycle 14. For parallel analysis of sis-a, sis-b, and $S \times l$, Canton-S embryos were prepared (0-to 3.5 -hr collections) and processed together until separated for the hybridization reactions. Subsequent steps were done in parallel under identical conditions. Staging of precellular embryos was based on nuclear number, location, and density (Foe and Alberts 1983). The nuclei were visualized by UV fluorescence after DAPI staining $(0.5 \mathrm{mg} / \mathrm{ml}$ in PBS $)$. Staging landmarks included the distance of the nuclei from the surface (cycles 7-9), the arrival of the first nuclei at the surface and formation of pole buds (cycle 9), pole cell formation (cycle 10), clearing of the cortical cytoplasm (late cycle 12, early cycle 13 ), and formation of membrane furrows (cycle 14). Embryos were judged to express RNA if staining was darker than observed with a control sense strand probe and if they could be distinguished from earlier (or later) embryos within the same preparation by their staining intensity.

\section{Genetic analysis}

Unless otherwise stated, mutations and chromosomes are described in Lindsley and Zimm (1992). The data on male-lethal effects of the double sis ${ }^{+}$duplication presented in Results were generated from crosses involving y $w \mathrm{~cm} \mathrm{Sx}]^{f 1} \mathrm{ct} / \mathrm{Y} ; P\left[A 1\left(\mathrm{w}^{+}\right.\right.$, sis- $\left.\left.a^{+}\right)\right] 4, P\left[B 5\left(w^{+}, s i s-b^{+}\right)\right] 22 / C y O$ males. Although the malelethal data presented in the text and in Table 2 were generated with sis- $a^{+}$transgenes that also carried $1(1) 10 B b^{+}$, the later gene did not contribute to the effects on male viability. Equivalent male-specific lethal interactions were observed for the sis$a^{+} 1(1) 10 B b^{-}$and sis- $a^{+} 1(1) 10 B b^{+}$transgenes in combination with the $s i s-b^{+}$duplication carried by the Binsinscy balancer chromosome. Moreover, no such male-lethal effects were observed with the sis- $a^{-}, 1(1) 10 B b^{+}$transgene.

The animals used to determine the sis- $b$ TSP were generated from a cross of $s i s-b^{s c 3-1} /$ Binsinscy females to $s i s-b^{s c 3-1} / Y$ males. Similar results were obtained with crosses of $s i s-b^{\text {sc3-1 }}$ homozygous females. Egg collections were for the periods indicated by the age intervals under the bars in Figure $9 \mid 30,60$, or $120 \mathrm{~min})$. Temperature shifts were made by transferring the containers from an air incubator to a temperature-controlled water bath at the times indicated. In contrast to the effect on sex determination, the proneural (bristle) aspect of this allele's phenotype was found not to be temperature sensitive in any consistent fashion even when hemizygous in $\mathrm{Sxl}^{M}$ females.

\section{Acknowledgments}

We are extremely grateful to R. Binari and N. Perrimon for generously providing us with cosmid clones that covered the sis-a region. We thank the following people for helpful discussions and/or comments on the manuscript: Chantal Akerib, Thomas Alber, Barbara Meyer, Erin O'Shea, Mark Samuels, Robert Tjian, and Charles Vinson. This work was supported by U.S. Public Health Service grant GM23468 to T.W.C. from the National Institutes of Health. J.W.E. is a SmithKline and Beecham fellow of the Life Sciences Research Foundation.

The publication costs of this article were defrayed in part by payment of page charges. This article must therefore be hereby marked "advertisement" in accordance with 18 USC section 1734 solely to indicate this fact.

\section{Note added in proof}

The nucleotide sequence data reported in this paper have been submitted to the GenBank, EMBL, and DDBJ data libraries under accession number L22755.

\section{References}

Anderson, K.V. and J.A. Lengyel. 1979. Rates of synthesis of major classes of RNA in Drosophila embryos. Dev. Biol. 70: $217-231$.

Bell, L.R., E.M. Maine, P. Schedl, and T.W. Cline. 1988. Sexlethal, a Drosophila sex determination switch gene, exhibits sex-specific RNA splicing and sequence similarity to RNA binding proteins. Cell 55: 1037-1046.

Bell, L.R., J.I. Horabin, P. Schedl, and T.W. Cline. 1991. Positive autoregulation of Sex-lethal by alternative splicing maintains the female determined state in Drosophila. Cell 65: 229-239.

Bengal, E., L. Ransone, R. Scharfmann, V.J. Dwarki, S.J. Tapscott, H. Weintraub, and I.M. Verma. 1992. Functional antagonism between c-Jun and MyoD proteins: A direct physical association. Cell 68: 507-519.

Bier, E., H. Vaessin, S. Younger-Shepherd, L.Y. Jan, and Y.N. Jan. 1992. deadpan, an essential pan-neural gene in Drosophila, encodes a helix-loop-helix protein similar to the hairy gene product. Genes \& Dev. 6: 2137-2151.

Bopp, D., L.R. Bell, T.W. Cline, and P. Schedl. 1991. Developmental distribution of female specific Sex-lethal proteins in Drosophila. Genes \& Dev. 3: 1288-1300.

Bridges, C.B. 1916. Non-disjunction as proof of the chromosome theory of heredity. Genetics 1: 1-52.

1921. Triploid intersexes in Drosophila melanogaster. Science 54: 252-254.

1925. Sex in relation to chromosomes and genes. Am. Nat. 59: 127-137.

Cabrera, C.V. and M.C. Alonzo. 1991. Transcriptional activation by heterodimers of the achaete-scute and daughterless gene products of Drosophila. EMBO I. 10: 2965-2973.

Cabrera, C.V., A. Martinez-Arias, and M. Bate.1987. The expression of three members of the achaete-scute gene complex correlates with neuroblast segregation in Drosophila. Cell 50: $425-433$.

Cline, T.W. 1978. Two closely linked mutations in Drosophila melanogaster that are lethal to opposite sexes and interact with daughterless. Genetics 90: 683-698.

- 1979. A male-specific lethal mutation in Drosophila melanogaster that transforms sex. Dev. Biol. 95: 260-274.

- 1980. Maternal and zygotic sex-specific gene interactions in Drosophila melanogaster. Genetics 96 903-926.

. 1983. The interaction between daughterless and Sexlethal in triploids: A lethal sex-transforming maternal effect linking sex determination and dosage compensation in Drosophila melanogaster. Dev. Biol. 95: 260-274.

- 1984. Autoregulatory functioning of a Drosophila gene product that establishes and maintains the sexually determined state. Genetics 107: 231-277.

- 1986. A female-specific lesion in an X-linked positive regulator of the Drosophila sex determination gene, Sex-lethal. Genetics 113: 641-663 (corrigendum 114: 345).

. 1988. Evidence that sisterless- $a$ and sisterless- $b$ are two of several discrete "numerator elements" of the X : A sex determination signal in Drosophila that switch Sex-lethal between two alternative stable expression states. Genetics 119: 829-862.

- 1993. The Drosophila sex determination signal: How do flies count to two? Trends Genet. (in press).

Daga, A., J.E. Tighe, and F. Calabi. 1992. Leukaemia/Drosophila homology. Nature 356: 484.

Driever, W., G. Thoma, and C. Nüsslein-Volhard. 1989. Determination of spatial domains of zygotic gene expression in the Drosophila embryo by the affinity of binding sites for the 
bicoid morphogen. Nature 340: 363-367.

Duffy, J.B. and J.P. Gergen. 1991. The Drosophila segmentation gene runt acts as a position-specific numerator element necessary for the uniform expression of the sex-determining gene Sex-lethal. Genes \& Dev. 5: 2176-2187.

Ellenberger, T.E., C.J. Brandl, K. Struhl, and S.C. Harrison. 1992. The GCN4 basic region leucine zipper binds DNA as a dimer of uninterrupted a helices: Crystal structure of the proteinDNA complex. Cell 71: 1223-1237.

Erickson, J.W. and T.W. Cline. 1991. Molecular nature of the Drosophila sex determination signal and its link to neurogenesis. Science 251: 1071-1074.

Foe, V.E. and B.M. Alberts. 1983. Studies of nuclear and cytoplasmic behavior during the five mitotic cycles that precede gastrulation in Drosophila embryogenesis. I. Cell. Sci. 61: $31-70$.

Gergen, P. 1987. Dosage compensation in Drosophila: Evidence that daughterless and Sex-lethal control X chromosomes activity at the blastoderm stage of embryogenesis. Genetics 117: 477-485.

Gorman, M., M.I. Kuroda, and B.S. Baker. 1993. Regulation of the sex-specific binding of the Maleless dosage compensation protein to the male X chromosome in Drosophila. Cell 72: 39-49.

Harland, R.M. 1991. In situ hybridization: An improved whole mount method for Xenopus embryos. Methods Cell Biol. 36: 685-695.

Herschlag, D. and F.B. Johnson. 1993. Synergism in transcriptional activation: A kinetic view. Genes \& Dev. 7: 173-179.

Ip, Y.T., R.E. Park, D. Kosman, E. Bier, and M. Levine. 1992a. The dorsal gradient morphogen regulates stripes of rhomboid expression in the presumptive neuroectoderm of the Drosophila embryo. Genes \& Dev. 6: 1728-1739.

Ip, Y.T., R.E. Park, D. Kosman, K. Yazdanbakhsh, and M. Levine. 1992b. dorsal-twist interactions establish snail expression in the presumptive mesoderm of the Drosophila embryo. Genes \& Dev. 6: 1518-1530.

Jiang, J. and M. Levine. 1993. Binding affinities and cooperative interactions with bHLH activators delimit threshold responses to the dorsal gradient morphogen. Cell 72: 741-752.

Jiang, J., D. Kosman, Y.T. Ip, and M. Levine 1991. The dorsal morphogen gradient regulates the mesoderm determinant twist in early Drosophila embryos. Genes \& Dev. 5: 18811891.

Kania, M.A., S.S. Bonner, J.B. Duffy, and P. Gergen. 1990. The Drosophila segmentation gene runt encodes a novel regulatory protein that is also expressed in the developing nervous system. Genes \& Dev. 4: 1701-1713.

Keyes, L.N., T.W. Cline, and P. Schedl. 1992. The primary sex determination signal of Drosophila acts at the level of transcription. Cell 68: 993-943 (corrigendum 68: 3).

Klämbt, C., J.R. Jacobs, and C.S. Goodman. 1991. The midline of the Drosophila central nervous system: A model for the genetic analysis of cell fate, cell migration, and growth cone migration. Cell 64: 801-815.

Kunkel, T.A. 1985. Rapid and efficient site-specific mutagenesis without phenotypic selection. Proc. Natl. Acad. Sci. 82: 488-492.

Lamb, M.M. and C.D. Laird. 1976. Increase in nuclear poly(A)containing RNA at syncytial blastoderm in Drosophila melanogaster embryos. Dev. Biol. 52: 31-42.

Landshulz, W.H., P.F. Johnson, and S.L. McKnight. 1989. The DNA binding domain of the rat liver nuclear protein C/EBP is bipartite. Science 243: 1681-1688.

Lindsley, D.L. and G.G. Zimm. 1992. The genome of Drosophila melanogaster. Academic Press, San Diego, CA.
Lucchessi, J.C. and T. Skripsky. 1981. The link between dosage compensation and sex differentiation in Drosophila melanogaster. Chromosoma 82: 217-227.

Lupas, A., M. Van Dyke, and J. Stock. 1991. Predicting coiled coils from protein sequences. Science 252: 1162-1164.

Maine, E.M., H.K. Salz, P. Schedl, and T.W. Cline. 1985. Sexlethal, a link between sex determination and sexual differentaion in Drosophila melanogaster. Cold Spring Harbor Symp. Quant. Biol. 50: 595-604.

McGrew, L.L., E. Dworkin-Rastl, M.B. Dworkin, and J.D. Richter. 1989. Poly(A) elongation during Xenopus oocyte maturation is required for translational recruitment and is mediated by a short sequence element. Genes \& Dev. 3: $803-815$.

McKeown, M., J.M. Belote, and R.T. Boggs. 1988. Ectopic expression of the female transformer gene product leads to female differentiation of chromosomally male Drosophila. Cell 53: 887-895.

Murre, C., P.S. McCaw, and D. Baltimore. 1989a. A new DNA binding and dimerization motif in immunoglobulin enhancer binding, daughterless, $M y o D$, and myc proteins. Cell 56: 777-783.

Murre, C., P.S. McCaw, H. Vaessin, M. Caudy, L.Y. Jan, Y.N. Jan, C.V. Cabrera, J.N. Buskin, S.D. Hauschka, A.B. Lassar, H. Weintraub, and D. Baltimore. 1989b. Interactions between heterologous helix-loop-helix proteins generate complexes that bind specifically to a common DNA sequence. Cell 58: 537-544.

O'Connell, P. and M. Rosbash. 1984. Sequence, structure, and codon preference of the Drosophila ribosomal protein 49 gene. Nucleic Acids Res. 12: 5495-5513.

O'Shea, E.K., J.D. Klemm, P.S. Kim, and T. Alber. 1991. X-ray structure of the GCN4 leucine zipper, a two-stranded, parallel, coiled coil. Science 254: 539-544.

O'Shea, E.K., R. Rutkowski, and P.S. Kim. 1992. Mechanism of specificity in the Fos-Jun oncoprotein heterodimer. Cell 68: 699-708.

Parkhurst, S.M. and D. Ish-Horowicz. 1992. Common denominators for sex. Curr. Biol. 2: 629-631.

Parkhurst, S.M., D. Bopp, and D. Ish-Horowicz. 1990. X : A ratio, the primary sex determining signal in Drosophila is transduced by helix-loop-helix proteins. Cell 63: 11791191.

Parkhurst, S.M., H.D. Lipshitz, and D. Ish-Horowicz. 1993. achaete-scute feminizing activities and Drosophila sex determination. Development 117: 737-749.

Pignoni, F., E. Steingrimsson, and J.A. Lengyel. 1992. bicoid and the terminal system activate tailless in the early Drosophila embryo. Development 115: 239-251.

Pirrotta, V. 1988. Vectors for P-mediated transformation in Drosophila. In Vectors, a survey of molecular cloning vectors and their uses (ed. R.L. Rodriguez and D.T. Denhardt), pp. 437-456. Butterworths, Boston, MA.

Poole, S., L. Kauvar, B. Drees, and T. Kornberg. 1985. The engrailed locus of Drosophila: Structural analysis of an embryonic transcript. Cell 40: 37-43.

Poulson, D.F. 1950. Histogenesis, organogenesis and differentiation in the embryo of Drosophila melanogaster meigen. In Biology of Drosophila (ed. M. Demerec), pp. 168-274. Wiley, New York.

Robinow, S., A.R. Compos, K.-M. Yo, and K. White. 1988. The elav gene product of Drosophila, required in neurons, has three RNP consensus motifs. Science 242: 1570-1572.

Sambrook, J., E.F. Fritsch, and T. Maniatis. 1989. Molecular cloning: A laboratory manual, 2nd ed. Cold Spring Harbor Laboratory Press, Cold Spring Harbor, New York.

Samuels, M.E., P. Schedl, and T.W. Cline. 1991. The complex 
set of late transcripts from the Drosophila sex determination gene Sex-lethal encodes multiple related polypeptides. Mol. Cell Biol. 11: 3584-3602.

Sanchez, L. and R. Nöthiger. 1982. Clonal analysis of Sex-lethal, a gene needed for female sexual development in Drosophila melanogaster. Wilhelm Roux's Arch. Dev. Biol. 191: 211214.

-1983. Sex determination and dosage compensation in Drosophila melanogaster: Production of male clones in $\mathrm{XX}$ females. $E M B O$ /. 2: 485-491.

Schule, R., R. Rangarajan, S. Kliewer, L.J. Ransome, J. Bolado, N. Yang, I.M. Verma, and R.M. Evans. 1990. Functional antagonism between oncoprotein c-Jun and the glucocorticoid receptor. Cell 62: 1217-1226.

Shermoen, A.W. and P.H. O'Farrell. 1991. Progression of the cell cycle through mitosis leads to the abortion of nascent transcripts. Cell 67: 303-310.

Small, S., S. Blair, and M. Levine. 1992. Regulation of evenskipped stripe 2 in the Drosophila embryo. EMBO $J$. 11: 4047-4057.

Sonnenblick, B.P. 1950. The early embryology of Drosophila melanogaster. In Biology of Drosophila (ed. M. Demerec), pp. 62-167. Wiley, New York.

Spradling, A.C. 1986. P element-mediated transformation. In Drosophila: A practical approach (ed. D.B. Roberts), pp. 175198. IRL Press, Oxford, England.

Struhl, G., K. Struhl, and P.M. MacDonald. 1989. The gradient morphogen bicoid is a concentration-dependent transcriptional activator. Cell 57: 1259-1273.

Tautz, D. and C. Pfeifle. 1989. A non-radioactive in situ hybridization method for the localization of specific RNAs in the Drosophila embryo reveals translational control of the segmentation gene hunchback. Chromosoma 98: 81-85.

Torres, M. and L. Sanchez. 1989. The scute (T4) gene acts as a numerator element of the $\mathrm{X}$ : A signal that determines the state of activity of Sex-lethal in Drosophila. EMBO J. 8: 3079-3086.

- 1991. The sisterless-b function of the Drosophila gene scute is restricted to the stage when the $\mathrm{X}$ : A ratio determines the activity of Sex-lethal. Development 113: 715722.

- 1992. The segmentation gene runt is needed to activate Sex-lethal, a gene that controls sex determination and dosage compensation in Drosophila. Genet. Res. 59: 189-198.

Van Doren, M., H.M. Ellis, and J.W. Posakony. 1991. The Drosophila extramacrochaetae protein antagonizes sequence-specific DNA binding by daughterless/achaete-scute protein complexes. Development 113: 245-255.

Villares, R. and C.V. Cabrera. 1987. The achaete-scute complex of $D$. melanogaster: Conserved domains in a subset of genes required for neurogenesis and their homology to myc. Cell 50: $415-424$.

Vinson, C.R., P.B. Sigler, and S.L. McKnight. 1989. Scissors-grip model for DNA recognition by a family of leucine zipper proteins. Science 246: 911-916.

Vinson, C.R., T. Hai, and S.M. Boyd. 1993. Dimerization specificity of the leucine zipper containing bZIP motif upon DNA binding: Prediction and rational design. Genes \& Dev. 7: 1047-1058.

Yang-Yen, H., J. Chambard, Y. Sun, T. Smeal, T.J. Schmidt, J. Drouin, and M. Karin. 1990. Transcriptional interference between c-Jun and the glucocorticoid receptor: Mutual inhibition of DNA binding due to direct protein-protein interaction. Cell 62: 1205-1215.

Younger-Shepherd, S., H. Vaessin, E. Bier, L.Y. Jan, and Y.N. Jan. 1992. deadpan, an essential pan-neural gene encoding an
HLH protein, acts as a denominator element in Drosophila sex determination. Cell 70: 911-912.

Zalokar, M. 1976. Autoradiographic study of protein and RNA formation during early development of Drosophila eggs. Dev. Biol. 49: 425-437. 


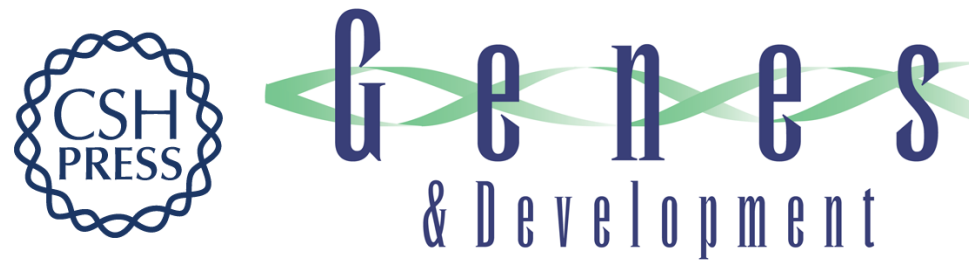

\section{A bZIP protein, sisterless-a, collaborates with bHLH transcription factors early in Drosophila development to determine sex.}

J W Erickson and T W Cline

Genes Dev. 1993, 7:

Access the most recent version at doi:10.1101/gad.7.9.1688

References This article cites 72 articles, 31 of which can be accessed free at: http://genesdev.cshlp.org/content/7/9/1688.full.html\#ref-list-1

License

Email Alerting

Service

Receive free email alerts when new articles cite this article - sign up in the box at the top right corner of the article or click here.

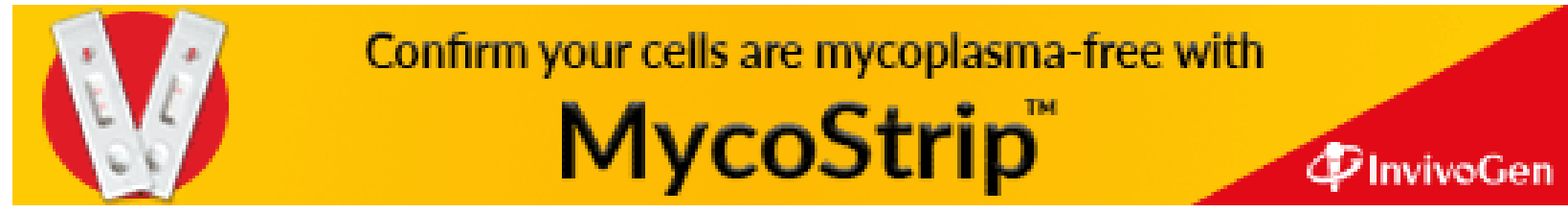

